\title{
Impacto en la geodinámica actual del valle de Nantoco, cuenca del río Copiapó, asociado a la reconversión productiva ${ }^{1}$
}

\author{
Carmen Paz Castro Correa², María Victoria Soto Bäuerle², \\ Roberto Fernández Torres², Michael Märker ${ }^{3}$ y Giuliano Rodolfi ${ }^{3}$
}

\section{RESUMEN}

La transformación productiva en el valle del río Copiapó comenzó a mediados de los años 70, con un aumento de la superficie plantada con parronales del orden del $236 \%$. Ello ha significado la introducción de modificaciones morfológicas, sobrepasando umbrales morfodinámicos, generando con esto diversos efectos sobre la dinámica morfológica. Estos impactos son significativos en dichos términos, ya que ha aumentado la vulnerabilidad a las remociones en masa que se producen durante episodios de lluvias intensas asociadas a años Niño, poniendo en riesgo a la población residente, a los trabajadores agrícolas, y generando importantes pérdidas en infraestructuras. Se presenta el caso de la cuenca de Nantoco, subcuenca del río Copiapó, que ha experimentado una notoria intervención humana durante las últimas tres décadas y que fue analizada en referencia a su comportamiento morfodinámico actual y la magnitud de su intervención.

Palabras clave: Sistemas de vertientes de cobertura, flujos de detritos, vulnerabilidad física.

\begin{abstract}
The change in productive land use in the Copiapó valley began in the mid seventies, with an increase in the area planted with bush vines in the order of $236 \%$. This has meant the introduction of significant morphological changes, exceeding in many places the morphodynamic thresholds, and generating impacts on the morphology dynamic. These impacts are significant in terms of increased vulnerability to mass removal occurring in episodes of heavy rains associated with the Niño years, with hazard for the resident population and agricultural workers, and in generating significant loss of infrastructure. We present the case of Nantoco basin, a sub-basin of the river Copiapó, which has experienced a notorious human intervention over the past three decades and which was analyzed in reference to its current morphodinamic behavior and the magnitude of its intervention.
\end{abstract}

Key words: Cover slope system, debris flow, physical vulnerability.

1 Artículo recibido el 14 de marzo de 2008 y aceptado el 16 de septiembre de 2008.

2 Departamento de Geografía, Universidad de Chile (Chile).E-mail: cpcastro@abello.dic.uchile.cl; mvsoto@uchile.cl; robferdt@gmail.com
3 Departamento de Ciencias del Suelo y Nutrición de la Planta, Universidad de Florencia (Italia). E-mail: michael.maerker@unifi.it; giuliano.rodolfi@unifi.it 
Chile se ha visto enfrentado en las últimas décadas a una rápida y creciente transformación territorial, derivada, en el caso del valle del río Copiapó, principalmente de los procesos de modernización agrícola. A su vez, los efectos de la globalización de la economía han traído consigo la aplicación de nuevas tecnologías y modos de ocupación de la tierra, lo que ha generado profundas intervenciones en la dinámica del paisaje natural.

En este contexto, el análisis y reconocimiento del paisaje es el medio para una mayor protección y manejo sustentable de los recursos naturales, previniendo de esta manera la generación o aceleración de determinados procesos geomorfológicos que pueden redundar en peligro y vulnerabilidad del medio, la población y la inversión productiva.

El reconocimiento de las componentes de geomorfología y suelos permite establecer las tendencias de cambio y evolución del territorio, las relaciones de integridad y/o degradación del paisaje, más aún cuando se asocia a los cambios de uso del suelo actual y proyectado.

El ambiente de desierto marginal del valle del río Copiapó presenta como característica morfoevolutiva la condición de un paisaje heredado, en donde sobresalen las formas debidas a la acción del agua, expresado en la intensa disección de las vertientes y los potentes depósitos aluviales, conformando taludes relictos. Esta situación ya fue descrita para el semiárido de Chile por Weischet (1968) y Soto et al. (2006), quienes dan cuenta de la presencia de formas relictas, pero con un funcionamiento dinámico actual y estacional en Chile central.

Esta condición dinámica estacional es una constante en el valle, que no solo se refiere a las condiciones naturales, sino también a las productivas, ligadas a la fuerte estacionalidad de la producción de vides. Desde el punto de vista de las condiciones físicas del territorio, este funcionamiento está vinculado a los eventos Niño, que reactivan el funcionamiento de las cuencas, con una gran torrencialidad, tal como lo registrado por Viles y Goudie (2003) e Iribarren (2007) en cuencas andinas del semiárido de Chile.
Por otra parte, las modificaciones en el paisaje natural debido a la modernización agrícola es un tema reconocido internacionalmente. Pelacani et al. (2006a y 2006b) señalan la importancia del análisis del suelo y de la erodabilidad del mismo, sobre todo en ambientes caracterizados por el alto impacto antrópico asociado a las modernas técnicas de cultivos y a la alteración topográfíca de las vertientes (viticultura en Toscana, Italia), con el consecuente aumento del riesgo de procesos de remoción en masa y erosión de suelo.

Entre las áreas más sensibles a estos procesos están aquellas en que el clima se caracteriza por la escasez o irregularidad meteorológica, con precipitaciones esporádicas e intensas, que aceleran considerablemente la erosión del suelo (Rodolfi, 2006), tal como ocurre en el semiárido chileno con las fluctuaciones del Niño.

Consecuentemente, el objetivo de esta investigación es analizar las implicancias de la reconversión productiva de las últimas décadas y el posible aumento de la vulnerabilidad a los efectos de los procesos geodinámicos que pueden representar riesgos en el valle, debido a las modificaciones e intensificación del uso del suelo. Ello implica el análisis de la dinámica natural, cambios en los patrones de producción agrícola e impactos geoedafológicos.

\section{Área de Estudio}

El análisis se centra en la subcuenca de Nantoco, tributaria del río Copiapó (Figura $N^{\circ} 1$ ). El área seleccionada corresponde a un sector que ha sufrido importantes modificaciones de su paisaje original debido a la instalación de cultivos de uva de exportación. Se considera también que la cuenca de Nantoco es representativa de un amplio sector del valle de Copiapó, en términos de sus características geográfico-físicas y de dominio morfoclimático, pudiendo dar cuenta de algunos patrones dinámicos recurrentes en el sistema mayor del río Copiapó.

El paisaje es característico del desierto marginal, en un ambiente de piso altitudinal de media a baja montaña, en que predominan tanto formas relictas como aquellas de- 
bidas a las condiciones ambientales actuales. La herencia geológica según Arévalo (2005) data del Mesozoico (jurásico superior-valangiano inferior).

\section{Metodología}

El valle de Nantoco se analizó desde la perspectiva de la evolución morfológica y evolutiva, la geodinámica actual del valle y los cambios de uso del suelo ocurridos en las últimas décadas, como parte de un sistema territorial altamente dinámico, sujetos a fluctuaciones climáticas en el marco de un paisaje relicto, propio del desierto marginal de Chile.

En este sentido, el estudio de la geodinámica consideró la intervención en las formas del paisaje y los cambios asociados, relacionados con un aumento de la inestabilidad y modificaciones en los suelos.

El análisis de los cambios en el uso del suelo permitió evaluar la intensidad de la reconversión productiva, el aumento de la superficie plantada y la presión sobre el recurso suelo.

La dimensión ambiental, por su parte, considera la evaluación del aumento de la cobertura vegetal, los efectos del uso intensivo en sectores de pendientes y las modificaciones mecánicas en las laderas.

El enfoque metodológico empleado se presenta en la Figura $\mathrm{N}^{\circ} 2$.



Fuente: Elaboración propia. 
Figura $\mathrm{N}^{\circ} 2$

Enfoque metodológico

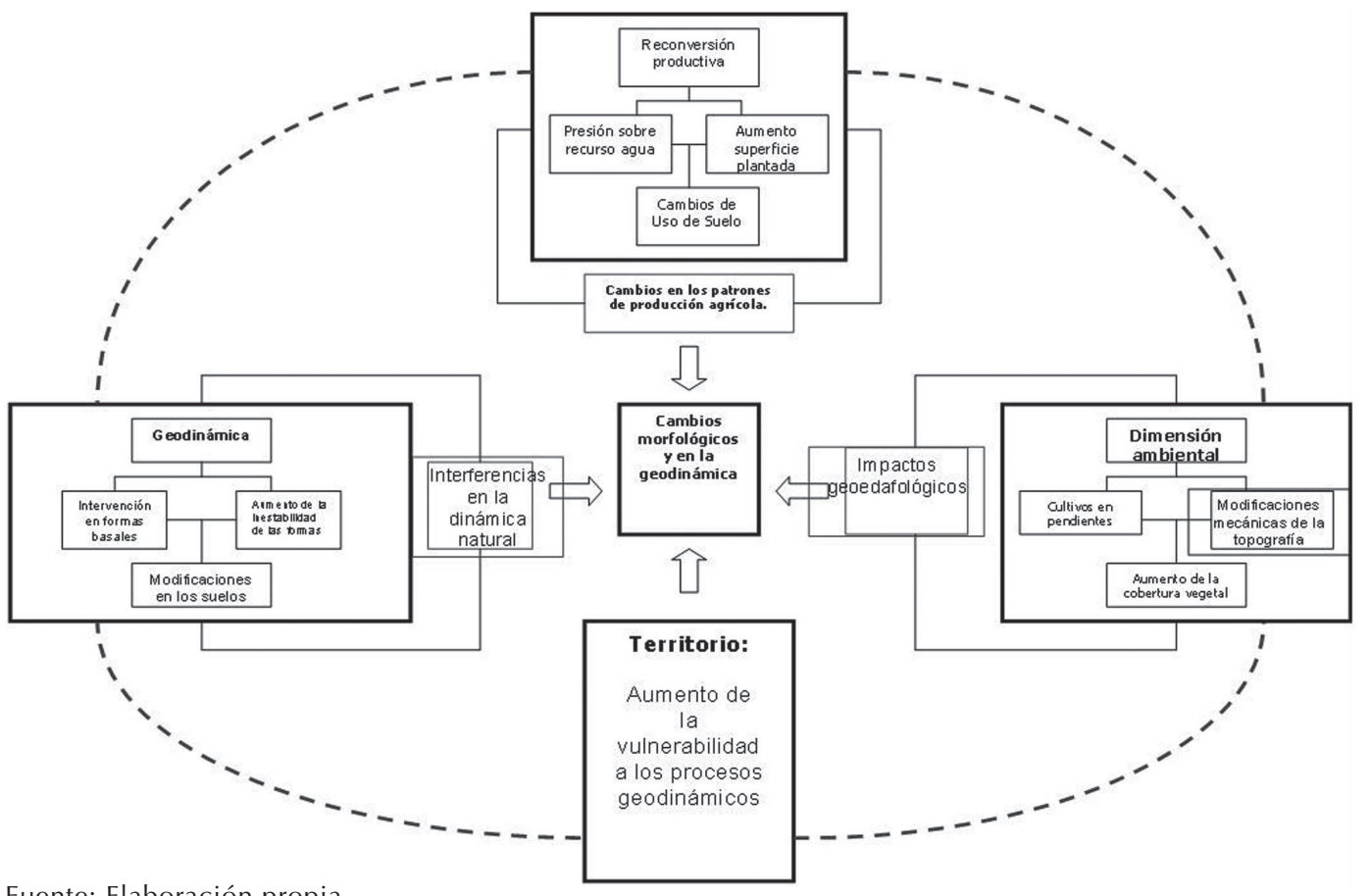

Fuente: Elaboración propia.

\section{Pasos metodológicos}

La geodinámica actual y morfología heredada fue abordada a través de la información de geología, estructura y tectónica de Arévalo (2005) y Segerstrom (1968). A partir de esta plataforma se realizó la carta de unidades morfolitológicas, en base a la clasificación de sistemas de vertientes de Araya-Vergara (1985), los trabajos de Soto et al. (2006 y 2007) y la consideración explícita de procesos actuales según Rapeti et al. (2005).

En la concepción de la carta geomorfológica se ha considerado la influencia estructural del paisaje, de la misma manera que los procesos dinámicos, tanto actuales como relictos. Las vertientes fueron abordadas como unidades integrales de geología y procesos dinámicos actuales, así como según su rol como aportadoras de masa, principalmente cuando se trata de vertientes modeladas en rocas estratificadas con afloramientos rocosos, desprovistas de vegetación y fuerte pendiente (Soto et al., 2007).
Las formas basales se representaron cartográficamente según génesis, de acuerdo a la clasificación de Araya-Vergara (1985), destacando los procesos dinámicos actuales, principalmente las evidencias de erosión, flujos de detritos y lechos torrenciales.

La carta geomorfológica fue confeccionada en base a fotointerpretación y trabajo de terreno (octubre y diciembre de 2007), destacando los procesos dinámicos actuales relacionados a la litología.

La componente suelo fue analizada a través de la información de IREN CORFO (1964). Se identificaron las series de suelos en función de la cartografía existente y de información obtenida en terreno. Se tomaron muestras compuestas de suelos de los primeros $20 \mathrm{~cm}$ (capa arable), las que fueron georreferenciadas con el uso de GPS tipo Garmin. Las muestras fueron identificadas y Ilevadas al laboratorio del Instituto de Investigaciones Agropecuarias (INIA) para su análisis químico. Los análisis efectuados corres- 
ponden a $\mathrm{pH}$, conductividad eléctrica (CE), materia orgánica (\%MO), N, P, K disponibles y capacidad de intercambio catiónico (CIC).

Por otra parte, se determinó la erosividad, la que corresponde a un factor importante para la comprensión de los procesos geomorfológicos que tienen lugar en un territorio. Sin embargo, es un parámetro difícil de estimar en muchos lugares debido a la falta de registros pluviométricos. La determinación de la erosividad pluvial se realizó a partir de la aplicación del Índice Modificado de Fournier (Jordan y Bellinfante, 2000).

$$
I M F=\sum_{I=1}^{12} \frac{p^{2} i}{P t}
$$

Donde:

IMF es el Índice Modificado de Fournier. pi es la precipitación media mensual. Pt es la precipitación media anual.

De acuerdo a Corine - CEC (1992) y Jordan y Bellinfante (2000), la clasificación del Índice Modificado de Fournier (IMF) se realiza a partir de los rangos expuestos en el Cuadro $\mathrm{N}^{\circ} 1$.

\section{Cuadro $\mathrm{N}^{\circ} 1$}

Rangos de clasificación del Índice Modificado de Fourier (IMF)

\begin{tabular}{|c|l|}
\hline IMF $(\mathrm{mm})$. & Descripción \\
\hline$<60$ & Muy bajo \\
$60-90$ & Bajo \\
$90-120$ & Moderado \\
$120-160$ & Alto \\
$>160$ & Muy alto \\
\hline
\end{tabular}

Fuente: Elaboración propia.

La representación espacial del IMF se efectuó a través de la elaboración de polígonos de Thiessen, a partir de la información pluviométrica y la ubicación de las estacio- nes anteriormente mencionadas, y el método de Pizarro et al. (2003) y Sánchez San Román (2005), para obtener la superficie de influencia para cada estación. Estas áreas fueron adaptadas cartográficamente a las características del relieve, en función de las curvas de nivel, buscando la aproximación más adecuada a la realidad.

La determinación de la densidad vegetal se realizó mediante el análisis y la reclasificación del Índice Normalizado de Diferencias Vegetales (Normal Difference Vegetal Index, NDVI), el que fue obtenido de las bandas roja e infrarroja de las imágenes satelitales Landsat MSS del año 1975 y Landsat ETM del año 2007. Se emplearon los criterios de reclasificación (Cuadro $N^{\circ} 2$ ) de Märker et al. (2001), cuyos rangos de cobertura vegetal fueron validados para Chile por Fernández (2006).

Cuadro $\mathrm{N}^{\circ} 2$

Criterios de reclasificación de Märker, validados para Chile

\begin{tabular}{|l|c|}
\hline \multicolumn{1}{|c|}{ Cobertura Vegetal } & $\%$ \\
\hline Muy baja & $0-10$ \\
Baja & $10-25$ \\
Moderadamente baja & $25-50$ \\
Moderadamente alta & $50-75$ \\
Alta & $75-90$ \\
Muy alta & $90-100$ \\
\hline
\end{tabular}

Fuente: Fernández, 2006.

Se analizó, conjuntamente, la dinámica geomorfológica, las transformaciones territoriales y el uso del suelo, para clasificar la vulnerabilidad de las formas a procesos de remociones en masa.

\section{Resultados}

\section{Paisaje morfolitológico y condición geodinámica}

La historia geológica del valle del Copiapó y de Nantoco, descrita por Segerstrom (1968) y Arévalo (2005), da cuenta de un 
Figura $\mathrm{N}^{\circ} 3$

Unidades morfolitológicas y procesos asociados

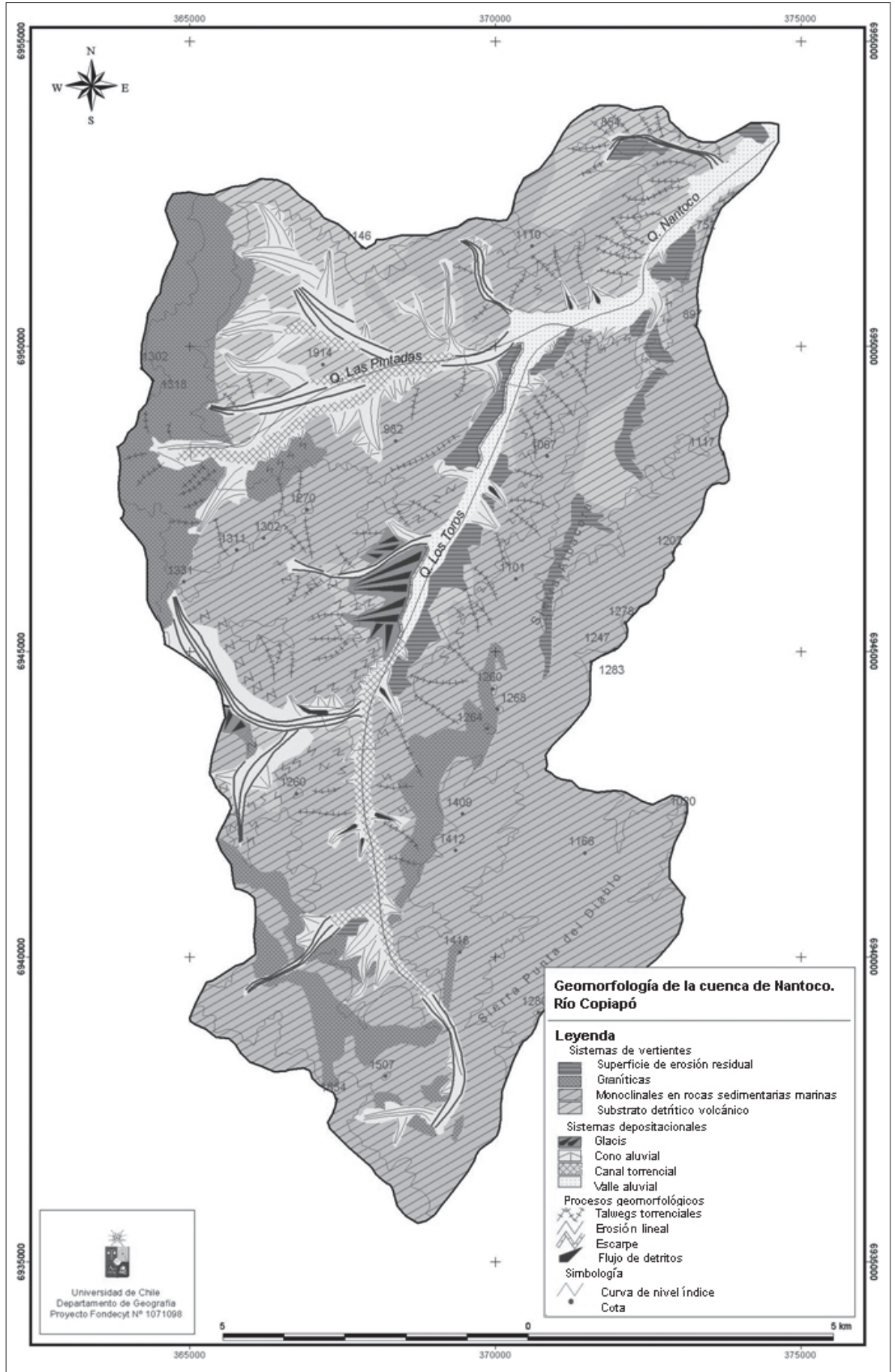

Fuente: Elaboración propia. 
paisaje conformado por vertientes plegadas tanto en substratos sedimentarios marinos (calizas), como en rocas de cobertura detrítico-volcánico y en substratos graníticos (Figura $\mathrm{N}^{\circ} 3$ ). La influencia estructural ha sido considerada como el factor que expresa la condición general del aporte potencial de masa desde las vertientes, debido a la exposición de los estratos rocosos.

Otro grupo de formas consideradas son los sistemas depositacionales de base de vertientes, que corresponden a sistemas de conos aluviales/glacis coluviales, formas interpretadas como indicadoras de la geodinámica heredada del Cuaternario en los sistemas de vertientes.

Como formas de depositación de fondo de valle, se consideraron los sistemas de conos aluviales/lechos fluviales, los que si bien son herencia del Cuaternario, presentan una condición dinámica actual no despreciable, toda vez que existen marcadas evidencias de arrastre de carga y disección de canales (Figura $N^{\circ} 4$ ). La presencia de lechos torrenciales anastomosados de fondo de valle, en la quebrada Los Toros, con evidencias de incisión de bancos, son formas indicativas de la condición dinámica de estos sistemas. Se aprecia el contacto entre las formas depositacionales de vertientes y los depósitos del talweg principal. Se advierte también la presencia de erosión lineal.

Desde el punto de vista de las mayores unidades morfolitológicas presentes en la cuenca, destaca territorialmente el dominio de los sistemas de vertientes modelados en estructuras plegadas compuestas por estratos sedimentarios marinos del Cretácico Inferior (calizas de la formación Nantoco), junto a sistemas modelados en rocas conformadas por secuencias sedimentarias y volcánicas (formación Punta del Cobre); estas unidades son intruidas por rocas graníticas del Cretácico Superior (Arévalo, 2005).

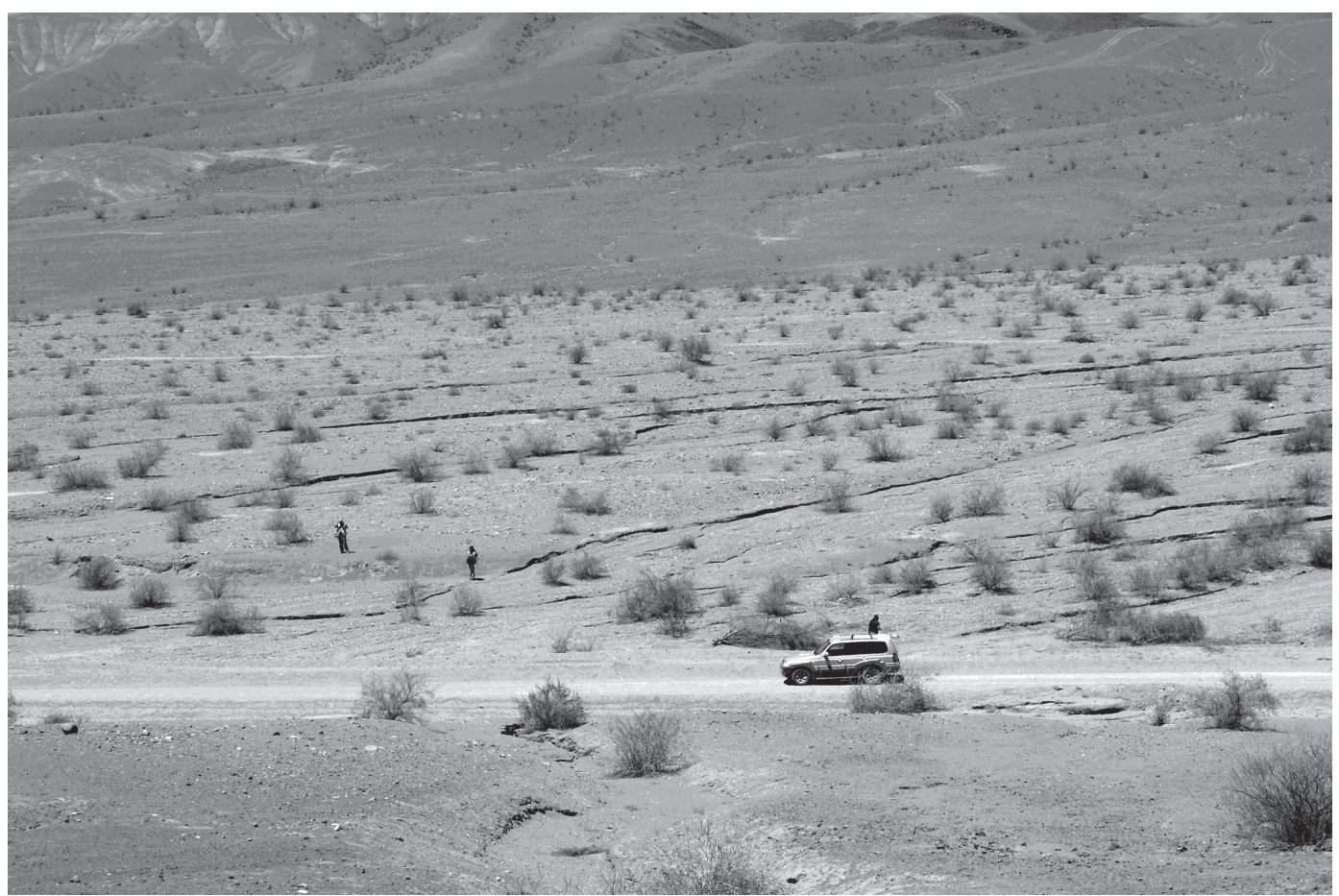

Fuente: Elaboración propia. 
Estas unidades conforman sistemas de vertientes con importantes afloramientos rocosos en superficie, mínima presencia de suelos y vegetación, donde solo es posible advertir una cobertura abierta de hierbas bajas y con formas heredadas que demuestran la actuación de procesos asociados a la acción del agua bajo condiciones ambientales diferentes a las actuales, pues las vertientes se encuentran profundamente incididas, con talwegs muy excavados. Asociado a estos sistemas se desarrollaron conos aluviales coalescentes de edad Cuaternaria (Arévalo, 2005).

Se observan en estos sistemas de laderas, patrones relacionados a los procesos evolutivos que han operado en estas. Se puede señalar la presencia de una extensa cobertura de detritos angulosos, que cubre prácticamente toda la ladera, sobre todo desde las partes medias hasta las secciones basales. Este patrón es recurrente a todos los sistemas de vertientes y en consecuencia han sido denominadas como vertientes de recubrimiento (Figura $\mathrm{N}^{\circ} 5$ ).

Estas evidencias de acciones dinámicas heredadas son recurrentes en toda la cuenca. Sin embargo, se observa un patrón diferencial en las vertientes esculpidas en rocas calizas. En ellas, a la condición de recubrimiento antes señalada, se adiciona la acción diferencial de la excavación por erosión lineal (rill), la cual es menor en los sistemas modelados en rocas de la Formación Nantoco, es decir, de rocas calcáreas.

El aspecto general de estas laderas de recubrimiento es bastante más suavizado que las demás, ya que presentan una lámina de sedimentos finos, de textura limo-arcillosa, que cumple el rol de sellado, de tal manera que se conforma un verdadero pavimento y reduce la vulnerabilidad a la erosión y la disección. Esta cobertura detrítica y pavimento es considerada como una condición evolutiva reciente de las laderas.

\section{Características de los suelos}

Los suelos del valle presentan características propias de suelos de zonas áridas, con uno o más horizontes pedogenéticos, un horizonte superficial de color claro y bajo en humus, pero que con riego pueden ser aptos para diversos cultivos. Corresponden a los órdenes de aridisoles y entisoles, de origen aluvial (Luzio y Casanova, 2006).

Estos suelos en general son de mala calidad, con texturas clasificadas como muy finas por IREN CORFO (1962/1963) y que, sin embargo, según los análisis de laboratorio realizados por esta investigación, muestran

Figura $\mathrm{N}^{\circ} 5$

Sistemas de vertientes de recubrimiento con formas de incisión profunda.

Detalle del recubrimiento detrítico y trabajo eólico en clastos de mayor tamaño (ventifactos), marzo de 2008

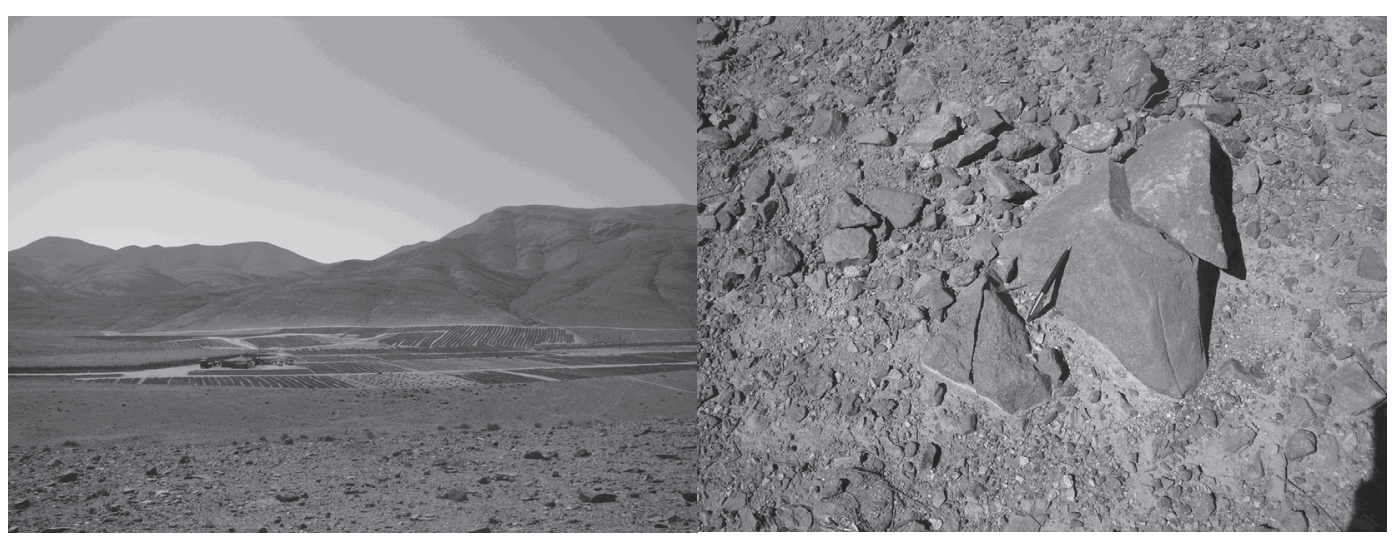

Fuente: Elaboración propia. 
una predominancia de las texturas medias, franca a franco arcillosa, a gruesas, arenosas a areno francosas.

Los suelos presentan alta salinidad, $\mathrm{pH}$ básico, CE alta, presencia de boro, sodio y cloro, entre otros. La reducción de la salinidad se constituye, entonces, en un costo que hay que agregar a los costos de producción, ya que genera, además, problemas de infiltración significativos. Estas limitaciones dificultan la producción agrícola y la diversificación de especies de uva, en momentos en que la competencia internacional por el mercado, especialmente de Estados Unidos y Europa, así lo requiere.

En general, las muestras analizadas de los suelos del valle de Nantoco (Figura $N^{\circ} 6$ ) presentan características fisicoquímicas que denotan una moderada a baja reactividad química, tratándose, en general, de suelos pobres desde un punto de vista de fertilidad.

Los suelos de las muestras 4, 5 y 7 presentan contenidos de potasio muy altos en oposición a los bajos contenidos de nitrógeno disponible (Cuadro $\mathrm{N}^{\circ} 3$ ).

Figura $\mathrm{N}^{\circ} 6$

Localización de muestras de suelo y textura

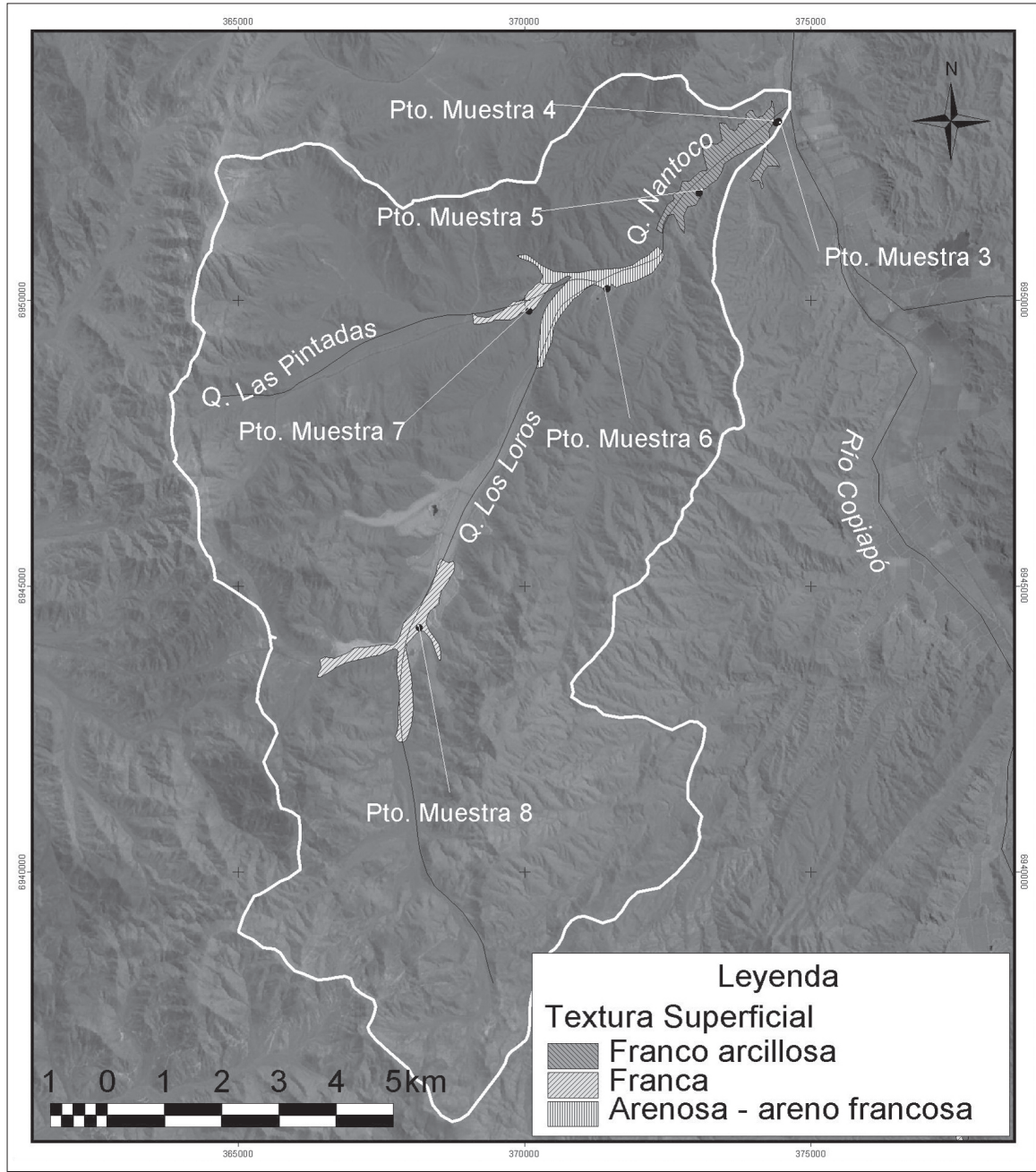

Fuente: Elaboración propia. 
Cuadro $\mathrm{N}^{\circ} 3$

Características de los suelos, valle de Nantoco. Análisis año 2007

\begin{tabular}{|c|c|c|c|c|c|c|c|c|}
\hline $\begin{array}{c}\text { Muestra } \\
\mathrm{N}^{\mathrm{o}}\end{array}$ & $\mathrm{pH}$ & $\begin{array}{c}\mathrm{C} . \mathrm{E} . \\
(\mathrm{Ms} / \mathrm{c})\end{array}$ & $\begin{array}{c}\mathrm{MO} \\
(\%)\end{array}$ & $\begin{array}{c}\mathrm{N} \\
\text { disponible } \\
(\mathrm{mg} / \mathrm{k})\end{array}$ & $\begin{array}{c}\mathrm{P} \\
\text { disponible } \\
(\mathrm{mg} / \mathrm{k})\end{array}$ & $\begin{array}{c}\mathrm{K} \\
\text { disponible } \\
(\mathrm{mg} / \mathrm{k})\end{array}$ & $\begin{array}{c}\mathrm{CIC} \\
\mathrm{pH} 7,0 \\
(\mathrm{Cm}+/ \mathrm{k})\end{array}$ & $\begin{array}{c}\text { Clase } \\
\text { textural }\end{array}$ \\
\hline 3 & 7,90 & 25,3 & 3,8 & 26 & 34 & 1002 & 24,5 & $\mathrm{FA}$ \\
4 & 8,17 & 66,4 & 3,2 & 42 & 435 & 2916 & 15,5 & $\mathrm{Fa}$ \\
5 & 8,48 & 7,9 & 0,5 & 21 & 5 & 473 & 10,7 & $\mathrm{Fa}$ \\
6 & 8,45 & 8,0 & 0,2 & 16 & 4 & 293 & 8,0 & $\mathrm{aF}$ \\
7 & 7,89 & 30,6 & 2,9 & 28 & 42 & 966 & 20,5 & $\mathrm{Fa}$ \\
\hline
\end{tabular}

Fuente: Elaboración propia.

Las muestras 5 y 6 presentan niveles bajos de fósforo mientras que las muestras 4 y 7 presentan valores elevados. Estos últimos contenidos pueden estar relacionados con el material generador de los suelos, es decir, rocas con alto contenido de potasio.

Respecto de la $\mathrm{CIC}$, sus valores demuestran que se trata de suelos con baja capacidad de interacción catiónica. Este atributo se relaciona, entre otros, con los contenidos escasos de materia orgánica de las muestras.

Todas las muestras se presentan en un rango de $\mathrm{pH}$ de ligeramente alcalino a alcalino, y la salinidad es elevada para la muestra 4.

La clase textural es media a gruesa (franco arenosa para las muestras 4,5 y 7, y areno francosa para la muestra 6), lo que puede dar un indicio de la baja capacidad de retención de humedad que presentan estos suelos.

\section{Cobertura vegetal}

La observación de las Figuras $\mathrm{N}^{0} 7$ y $\mathrm{N}^{0}$ 8 da cuenta de la cobertura vegetal del área en los años 1975 y 2007, con un significativo aumento de la superficie plantada con parronales en 30 años. En 1975 había 907 ha plantadas fundamentalmente con parronales de uva de mesa, con una cobertura vegetal predominantemente baja en el $89 \%$ de dicha área ( $<25 \%$ cobertura). En 2007, la superficie plantada aumentó a 2.138 ha, densificando la cobertura, ya que actual- mente en el valle el $56 \%$ de la superficie plantada tiene una cobertura moderadamente alta y alta $(>50 \%)$.

Se observa el significativo aumento de la cobertura con parronales en el período analizado, implicando así el aprovechamiento de las zonas de conos aluviales, alcanzando en los últimos años superficies con mayores pendientes. Peralta (2004) plantea que los suelos con pendientes superiores a $15 \%$ se clasifican como no aptos para el cultivo a causa del ángulo de inclinación, la susceptibilidad a la erosión y su escasa profundidad.

En este sentido, se puede señalar que en Chile no existe una normativa que regule el uso frutícola en zonas de laderas y solo a fines de 2005 el Servicio Agrícola y Ganadero publicó un manual de especificaciones técnicas con este fin, que pretende propiciar un manejo sustentable de los recursos naturales. Este manual no tiene carácter normativo, sino que constituye una orientación técnica para la toma de decisiones.

\section{Clasificación de uso del suelo}

Se aplicó la clasificación de Pelacani et al. (2005) para el uso del suelo, según la intensidad del cambio de uso que se ha producido. De esta manera se puede decir que en el valle de Nantoco la mayor parte del área ha sufrido un cambio de uso considerado de acción intensiva, que corresponde al área en la que se pasa de un cultivo menos especializado o de áreas sin cultivar, a áreas 
de una mayor presión sobre el territorio, como en este caso, de paisaje seminativo a cultivo intensivo de parronales.

Las zonas de laderas se clasifican como invariadas ya que no han sufrido cambios de uso ni ocupación. Se podría estimar que a futuro pudieren ser reconocidas también áreas a ser clasificadas como de acción extensiva, caracterizadas por estar sujetas a abandono de cultivos (Figura $N^{\circ}$ 9).

En general, toda el área presenta formas dinámicas actualmente en el límite de la expansión del área plantada, algunas de las cuales tienen mayor potencial de continuar avanzando por el modelado favorable con menores pendientes.

\section{Agresividad o erosividad pluvial}

Para el cálculo de la erosividad, se recurrió a antecedentes pluviométricos de las estaciones localizadas cerca del área de estudio, administradas por la Dirección General de Aguas (DGA); estas son: Elibor Campamento, Los Loros y Copiapó (Cuadro N ${ }^{\circ}$ ).

Se analizaron datos de las tres últimas décadas, distinguiendo aquellos años co-

Figura $\mathrm{N}^{0} 7$

Cobertura vegetal 1975

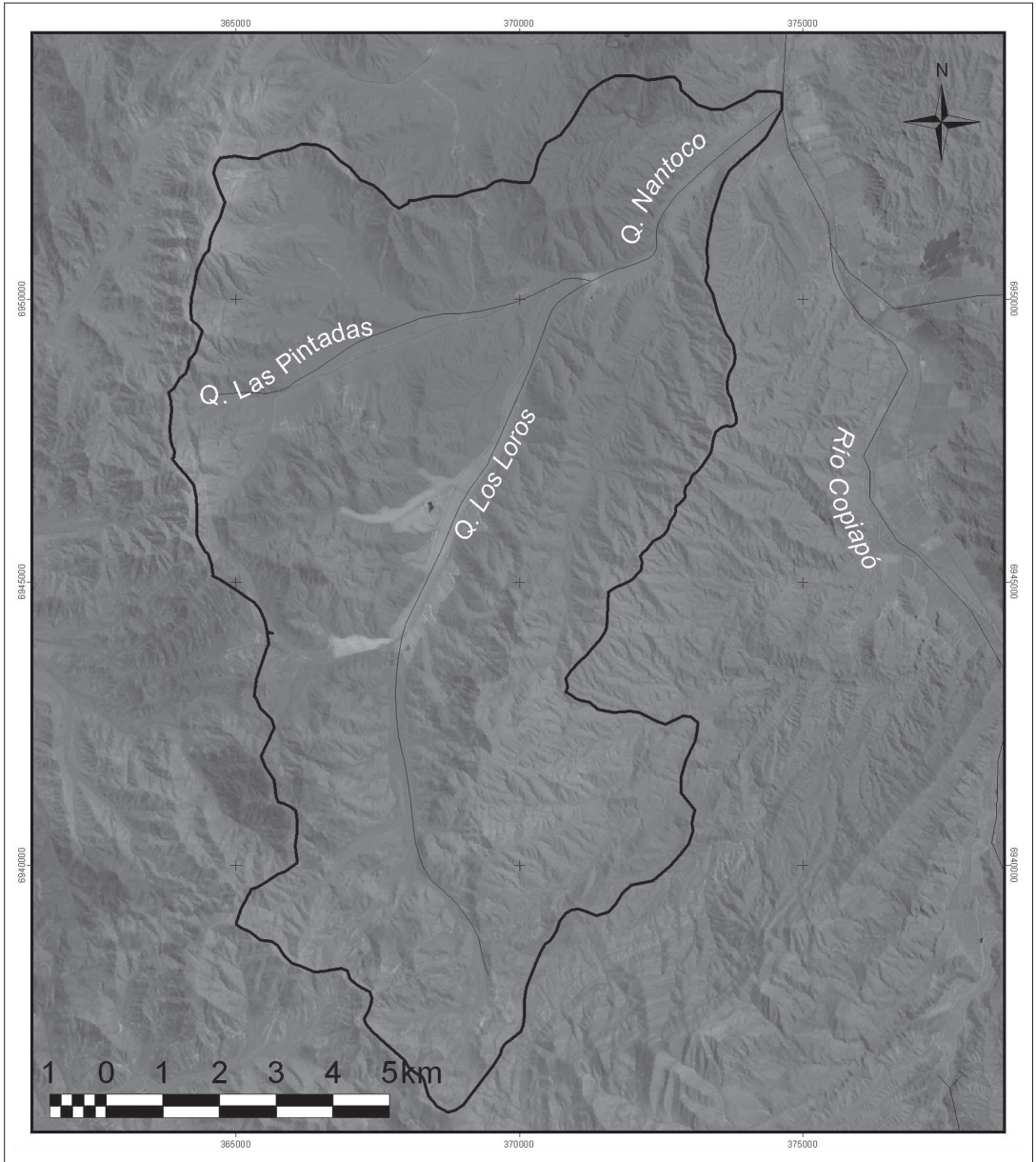

Fuente: Elaboración propia (leyenda en Figura $N^{\circ}$ 8). 
Cuadro $\mathrm{N}^{\circ} 4$

Precipitación e índices de erosividad pluvial

\begin{tabular}{|l|c|c|c|c|c|c|c|}
\hline \multirow{2}{*}{ Estación } & \multicolumn{2}{|c|}{ Coordenadas UTM } & $\begin{array}{c}\text { Período } \\
\text { de registro }\end{array}$ & $\begin{array}{c}\text { Altitud } \\
(\mathrm{m} . \mathrm{s.n.m.})\end{array}$ & $\begin{array}{c}\text { Pp media } \\
\text { anual } \\
(\mathrm{mm})\end{array}$ & $\begin{array}{c}\text { IMF } \\
(\mathrm{mm})\end{array}$ & $\begin{array}{c}\text { Grado de } \\
\text { erosividad }\end{array}$ \\
\cline { 2 - 8 } & Norte & Este & Copiapó \\
$\begin{array}{l}\text { Elibor } \\
\text { Campamento }\end{array}$ & 6.971 .037 & 368.392 & $1971-2006$ & $0-500$ & 18,6 & 38,1 & Muy bajo \\
\hline
\end{tabular}

Fuente: Elaboración propia.

Figura $\mathrm{N}^{\circ} 8$

Cobertura vegetal 2007

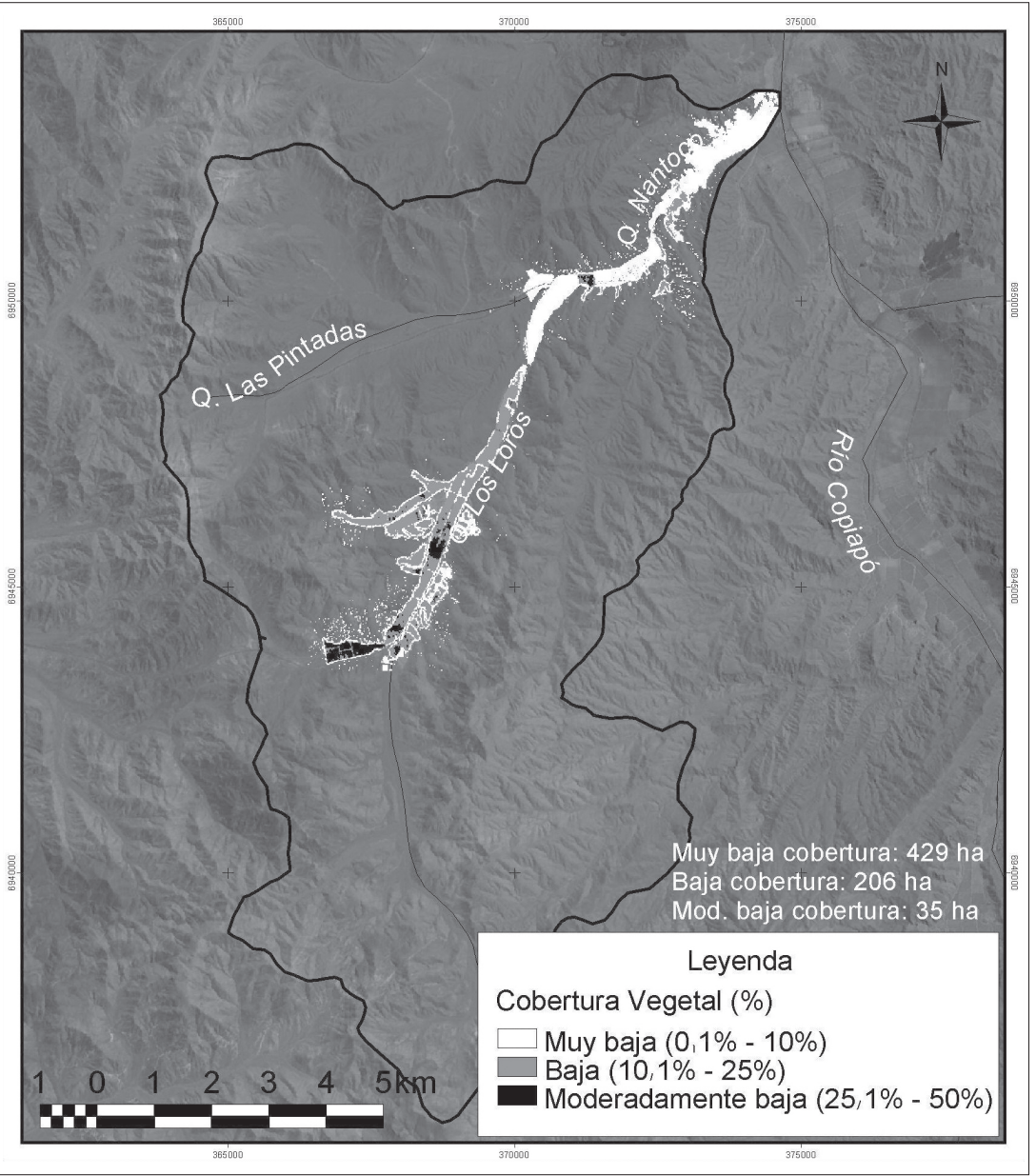

Fuente: Elaboración propia. 
rrespondientes a años Niño. El Cuadro $\mathrm{N}^{\circ} 4$ da cuenta de la poca variabilidad y escasa significancia de las precipitaciones para el período estudiado y un grado de erosividad consecuente. Al considerar solamente los años Niño, se aprecia la variación en el grado de erosividad pluvial (Cuadro $\mathrm{N}^{0} 5$ y Figura $\left.N^{\circ} 10\right)$, destacando el hecho que la gran parte de la cuenca Nantoco presenta un IMF de 123,62, considerado como alto. El sector de Las Pintadas, sección norte, correspondiente al área de influencia de la estación Copiapó, mantuvo su condición de erosividad muy baja.
Cuadro $\mathrm{N}^{\circ} 5$

IMF correspondiente a años Niño del período

\begin{tabular}{|l|c|c|}
\hline Estación & IMF & $\begin{array}{c}\text { Grado de } \\
\text { erosividad }\end{array}$ \\
\hline $\begin{array}{l}\text { Copiapó } \\
\text { Elibor } \\
\text { Campamento }\end{array}$ & 123,62 & Auy bajo \\
\hline
\end{tabular}

Fuente: Elaboración propia.

Figura $N^{\circ} 9$

Intensidad del cambio del uso del suelo

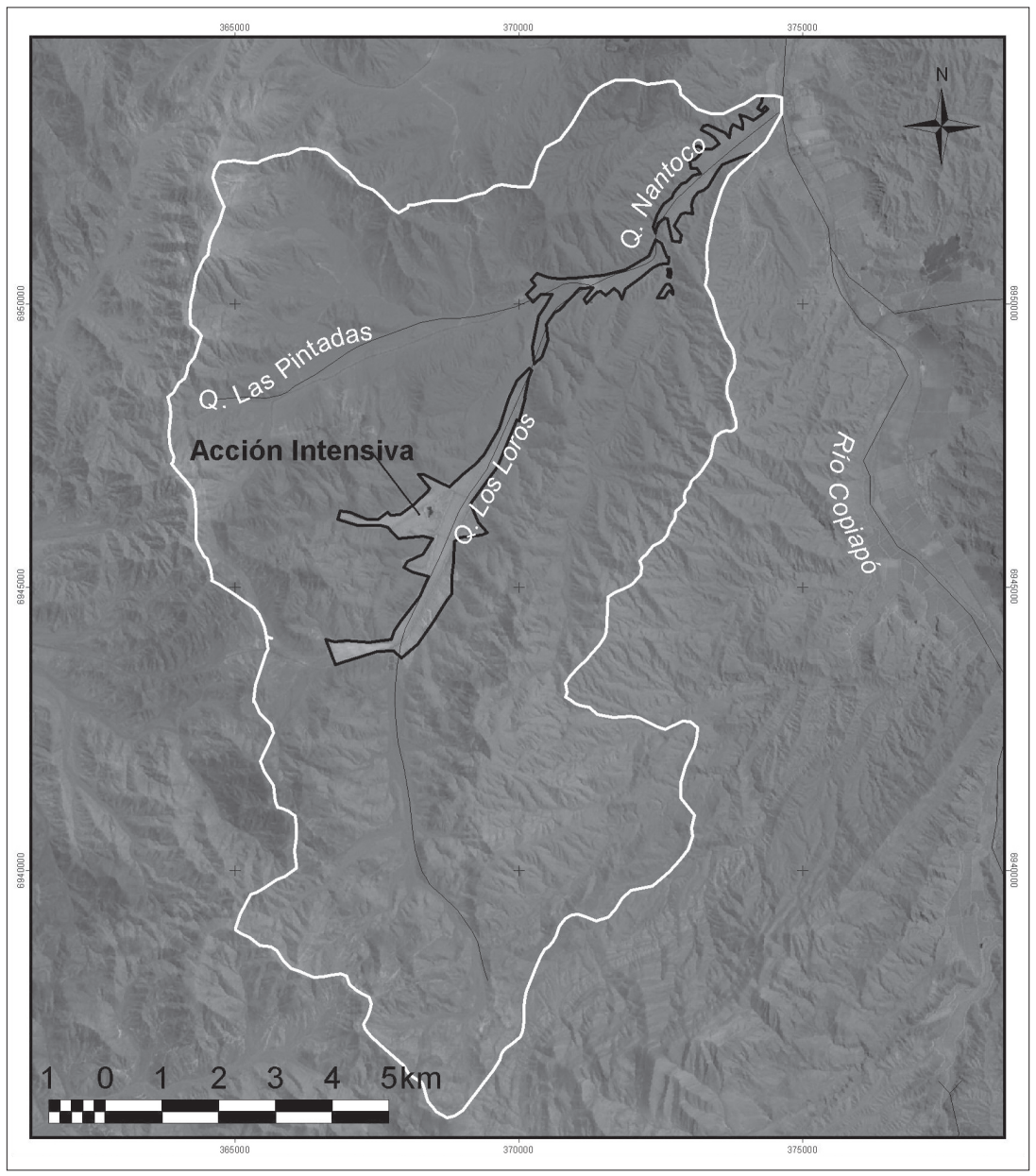

Fuente: Elaboración propia. 


\section{Impactos del cambio de uso: vulnerabilidad física}

A partir de la correlación de la intensidad de cambio de uso y la condición dinámica de las formas, se pudo establecer los impactos asociados a la incorporación de la agricultura en las diferentes formas, principalmente en las de carácter heredado, propias del valle de Nantoco y del semiárido chileno. Tales impactos han sido definidos como vulnerabilidad física del territorio (Cuadro $\mathrm{N}^{\circ}$ 6).
La naturaleza de las formas y del paisaje actual configuran un cuadro geodinámico especial, en la medida que las condiciones de vulnerabilidad expresadas son relativas a la ocurrencias de eventos pluviométricos concentrados, asociados a El Niño (ENSO). En este contexto, el aspecto actual del paisaje en general es de una muy baja condición geodinámica y, consecuentemente, también de vulnerabilidad física.

Sin embargo, las variables geodinámicas empleadas dan cuenta de la acción del agua en períodos recientes (evento 1997) y, con-

Figura $\mathrm{N}^{0} 10$

Agresividad pluvial para años con ocurrencia de fenómeno El Niño

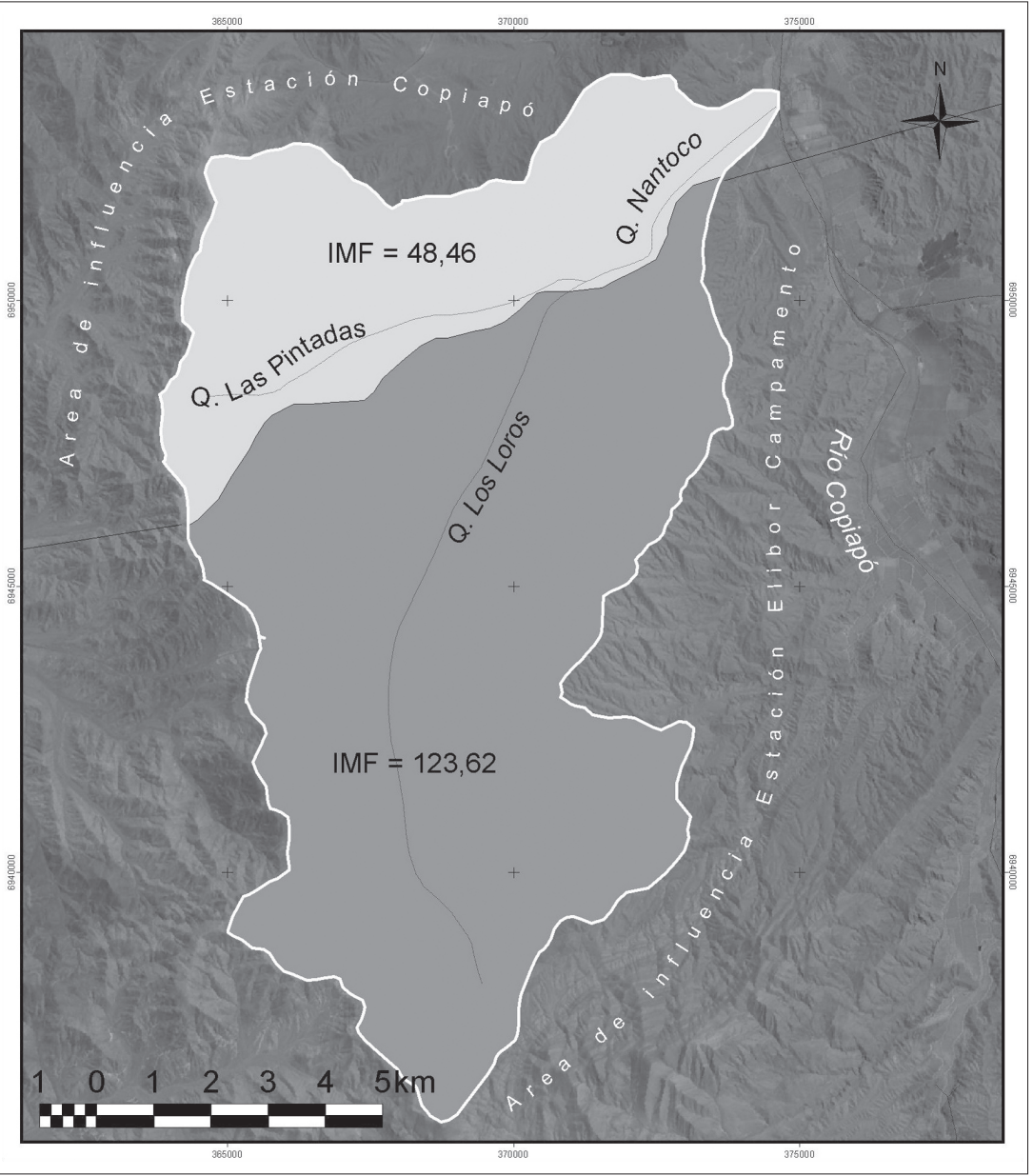

Fuente: Elaboración propia. 
secuentemente, a partir de estas evidencias morfológicas se establecieron los niveles de vulnerabilidad (Figura $N^{\circ} 11$ ).

Los sistemas de vertientes monoclinales modelados en rocas calcáreas presentan marcas de erosión lineal heredadas, talwegs torrenciales, rasgos actuales de actividad torrencial en conos aluviales y una detritificación intensa en las vertientes que funcionalmente actúa como una cobertura. A lo anterior, se debe agregar que existe un pavimento de limos calcáreos que recubre y estabiliza tales laderas, incidiendo en una me- nor condición de incisión lineal, y redundando en un lavado muy superficial. Estas condiciones permiten considerar este sector como de vulnerabilidad media. En estas unidades morfológicas no existen en la actualidad cultivos de parronales, pero la acción de difusión de masa puede incidir en el aumento de la vulnerabilidad de aquellos localizados en unidades contiguas, tales como los sistemas basales.

En esta misma línea de análisis destaca la condición dinámica y de vulnerabilidad de las superficies de erosión residual, que cons-

Figura $N^{0} 11$

Geomorfología y vulnerabilidad física del territorio, Nantoco

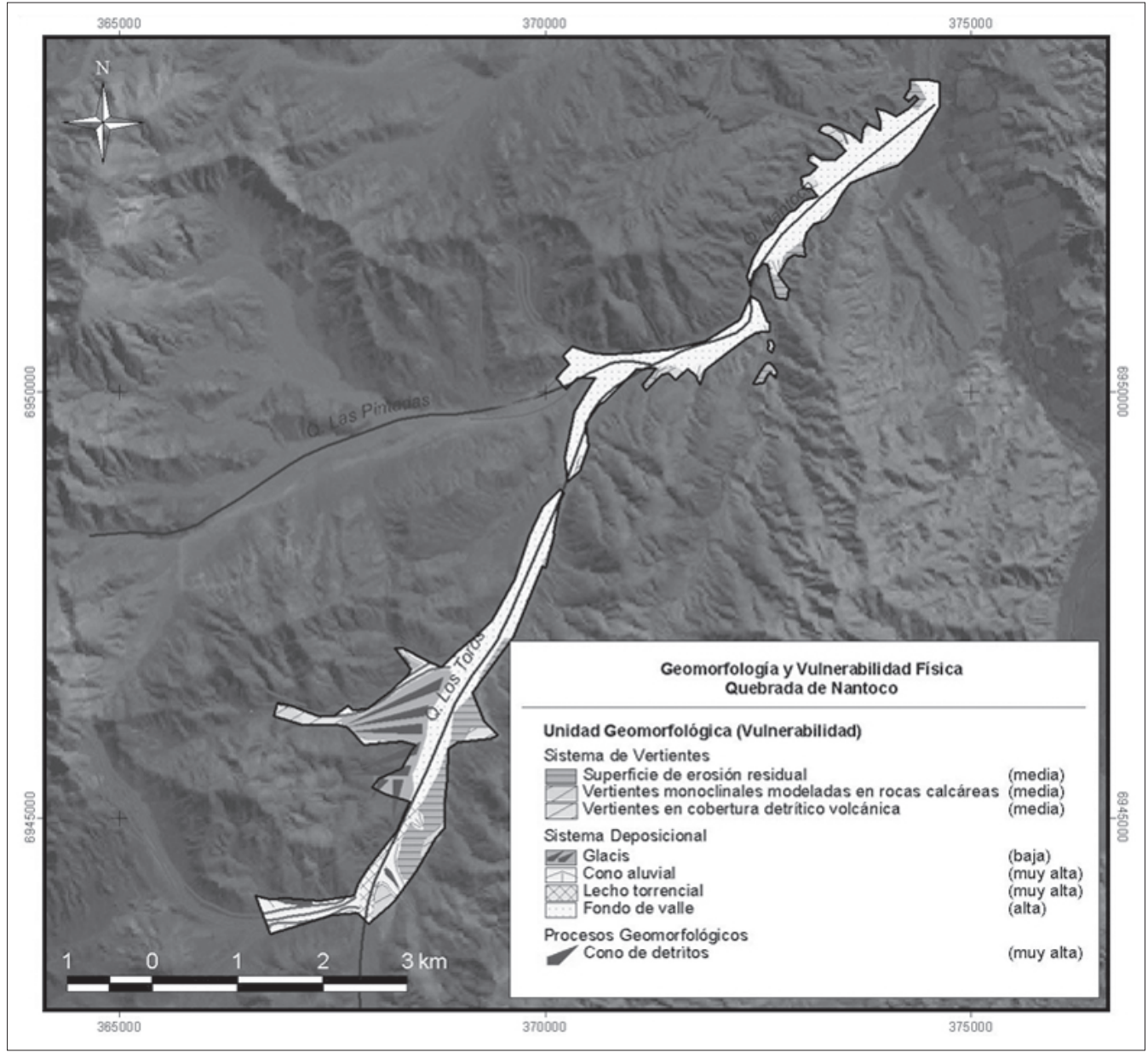

Fuente: Elaboración propia. 
tituyen formas de terrazas. Estas terrazas presentan una detritificación intensa y erosión lineal, en un ambiente de baja pendiente pero con un frente muy escarpado, que expone los materiales detríticos en un estado importante de consolidación. Si bien el nivel de geodinámica y de vulnerabilidad asociado es intrínsecamente bajo, estas unidades son altamente sensibles a cualquier intervención antrópica, que implique la remoción de la cobertura detrítica y pavimento calcáreo, como modificación de su perfil de equilibrio, situación bajo la cual adquieren una nueva condición geodinámica. Estos sectores están siendo incorporados al uso productivo (Figura $N^{\circ} 12$ ) a través de intervenciones en la topografía local de las formas.

Las unidades de mayor vulnerabilidad corresponden a los conos aluviales torrenciales, que si bien son formas muy puntuales y de una baja expresión territorial, su ca- pacidad de incisión y de arrastre de materiales es muy alta, conformando flujos de detritos altamente concentrados. Ello implica consecuentemente una alta vulnerabilidad e impacto territorial, toda vez que la difusión de masa es alta, dirigida a través de los talwegs hasta los fondos de valle. Los conos aluviales han sido históricamente incorporados al uso del suelo, tendencia que se mantiene en la actualidad.

A su vez, los fondos de valle, utilizados intensamente en la agricultura, presentan también una acción geodinámica alta, toda vez que ante eventos pluviométricos de mediana intensidad para la zona se reactiva su rol de emisarios de masa desde los sistemas de vertientes y de las formas depositacionales basales, a la manera de caudales torrenciales con sobrecarga de masa, modelando un claro patrón de lechos anastomosados actuales.

Figura $\mathrm{N}^{\circ} 12$

Terraza de superficie de erosión residual, en proceso de modificación topográfica e incorporación al uso agrícola (diciembre 2007)

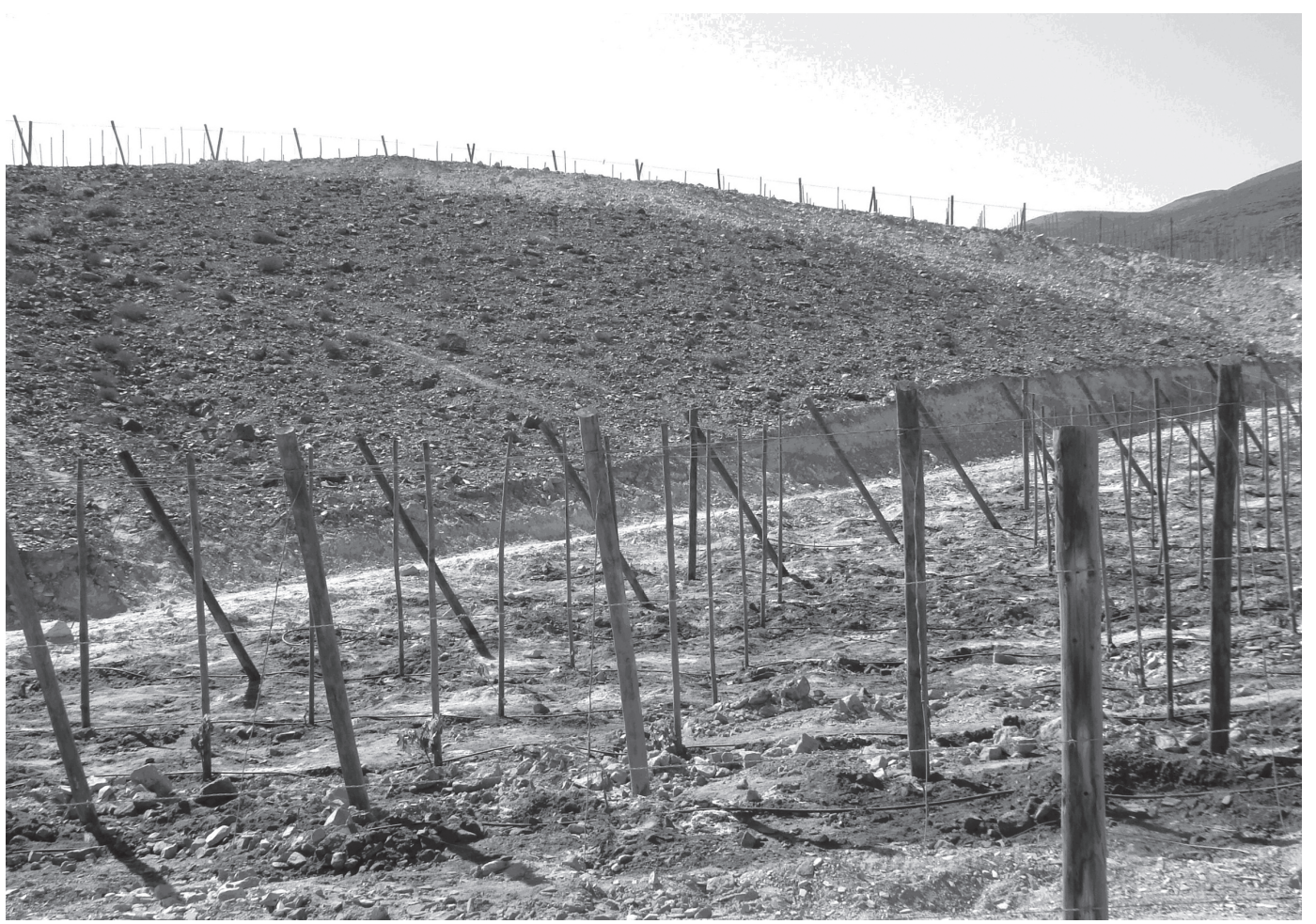

Fuente: Elaboración propia. 
Cuadro $\mathrm{N}^{\circ} 6$

Vulnerabilidad de las formas actuales y heredadas

\begin{tabular}{|c|c|c|}
\hline Geoformas & Geodinámica actual & Vulnerabilidad \\
\hline $\begin{array}{l}\text { Sistemas de vertientes monoclinales } \\
\text { en rocas calcáreas (vertientes de } \\
\text { cobertura) }\end{array}$ & $\begin{array}{l}\text { Erosión lineal } \\
\text { Detritificación intensa } \\
\text { Talwegs torrenciales } \\
\text { Actividad torrencial en conos } \\
\text { aluviales }\end{array}$ & Media \\
\hline $\begin{array}{l}\text { Sistemas de vertientes en cobertura } \\
\text { detrítico volcánica }\end{array}$ & $\begin{array}{l}\text { Erosión lineal } \\
\text { Detritificación intensa } \\
\text { Talwegs torrenciales }\end{array}$ & Media \\
\hline Superficie residual de erosión & $\begin{array}{l}\text { Erosión lineal } \\
\text { Detritificación intensa }\end{array}$ & Media \\
\hline Glacis & $\begin{array}{l}\text { Erosión lineal } \\
\text { Talwegs torrenciales }\end{array}$ & Baja \\
\hline Conos aluviales torrenciales & $\begin{array}{l}\text { Talwegs torrenciales } \\
\text { Flujos de detritos }\end{array}$ & Muy Alta \\
\hline Fondo de valle & $\begin{array}{l}\text { Lechos incididos, con patrones } \\
\text { anastomosados }\end{array}$ & Alta \\
\hline
\end{tabular}

Fuente: Elaboración propia.

\section{Consideraciones finales}

Desde el punto de vista del análisis de las componentes del territorio físico, las características del valle son propias del desierto marginal de Chile, con formas asociadas a condiciones climáticas diferentes de las actuales, conformando un paisaje relicto, en que la acción del agua fue uno de los agentes modeladores del territorio. No obstante las condiciones climáticas actuales de semiaridez, existe una condición geodinámica actual, no despreciable, asociada a la ocurrencia de los eventos Niño.

Tanto por lo observado en terreno, en cuanto a las evidencias de la acción torrencial de talwegs, fondos de valle y conos aluviales, junto con los resultados de una agresividad pluvial muy alta durante los eventos El Niño, es posible concluir que, si bien existe una condición generalizada de baja acción geodinámica, estos eventos generan situaciones de torrencialidad y transporte de masa significativos que dinamizan periódicamente el sistema.

En relación con la dimensión ambiental, en el período estudiado se observó, a través de la aplicación del NDVI, el significativo aumento de la cobertura vegetal, debido a las plantaciones de parronales de exportación. Desde esta perspectiva se podría concluir que la reconversión productiva ha generado un impacto positivo en el incremento de biomasa. Sin embargo, si se analizan las prácticas de manejo del suelo asociadas al incremento del uso de terrenos no aptos para la agricultura debido al aumento de la vulnerabilidad a sufrir procesos de erosión y remoción en masa, la conclusión no es tan clara.

En este contexto, estas prácticas han implicado las necesarias transformaciones topográficas de laderas y formas de base y 
modificado sus perfiles de equilibrio, por lo cual, ante eventos de precipitaciones concentradas asociadas a El Niño, existe una mayor disponibilidad de masa detrítica y es aumentada la torrencialidad de cursos de agua.

Por otra parte, la incorporación de suelos en cotas más elevadas, correspondiente a terrazas residuales, está en desarrollo, con la consecuente modificación topográfica del terreno, y los impactos ya descritos, pero de mayor intensidad, por la pendiente y la conformación sedimentológica.

A modo de conclusión general, existen impactos en la geodinámica actual del paisaje debido a la reconversión productiva, los que son de carácter negativo. El indicador de impacto geodinámico ha sido la vulnerabilidad física del territorio, determinada a partir del aumento de la vulnerabilidad de la cuenca ante precipitaciones concentradas, que constituye el principal agente detonador de procesos de carácter catastrófico a la escala de análisis.

\section{Referencias bibliográficas}

ARAYA-VERGARA, J. Análisis de la carta geomorfológica de la cuenca del Mapocho. Informaciones Geográficas, 1985, №32, p. 31-44.

ARÉVALO, C. Carta Los Loros, Región de Atacama. Carta geológica de Chile, serie geología básica. Santiago: Servicio Nacional de Geología y Minería (SERNAGEOMIN), 2005, N92.

CORINE - CEC. Soil erosion risk and important land resources. An assessment to evaluate and map the distribution of land quality and soil erosion risk. Luxemburgo: Ofice of official publications \& the European Communities, 1992.

FERNÁNDEZ, R. Evaluación de procesos erosivos y su influencia sobre el corredor de comercio Las Leñas: VI Región del Libertador Gral. Bernardo O'Higgins. Memoria título profesional de Geógrafo. Santiago: Escuela de Geografía, Facultad de Arquitectura y Urbanismo, Universidad de Chile, Chile, 2006.
IREN-CORFO. Suelos. Descripciones proyecto aerofotogramétrico. Santiago: Instituto de Información de Recursos Naturales CORFO, 1964, No 2 .

IRIBARREN, P. Glaciares rocosos en el semiárido chileno, su significado climático y geomorfológico. Análisis de caso. Cuenca superior del río La Laguna. Memoria título profesional de Geógrafo. Santiago: Escuela de Geografía, Facultad de Arquitectura y Urbanismo, Universidad de Chile, Chile, 2007.

JORDÁN, A. y BELLINFANTE, N. Cartografía de la erosividad de la lluvia estimada a partir de datos pluviométricos mensuales en el campo de Gibraltar (Cádiz). Revista Edafología, 2000, vol. 7, №3, p. 83-92.

LUZIO, W. y CASANOVA, M. Avances en el conocimiento de los suelos de Chile. Santiago: Servicio Agrícola Ganadero (SAG) \& Universidad de Chile, 2006.

MÄRKER, M.; MORETTI, S. \& RODOLFI, G. Assessment of water erosion processes and dynamics in semi-arid regions of Southern Africa (kwazulu / Natal, RSA, and Swaziland) using the Erosion Response Units concept (ERU). Geografia Fisica e Dinamica Cuaternaria, 2001, No 24, p. 71-83.

PELACANI, S.; UNGARO, F.; LOMBARDI, L. \& RODOLFI, G. Applicazione di techiche geostatistiche e GIS per la caratterizzazione dei suoli e della loro erodabilita. En: RODOLFI, G. Water erosion in mediterranean environment: direct and indirect assessment in test areas and catchments. Genova: Ministero dell Università e Della Ricerca Progetti di Rilevante Interesse Nazionale, 2006a.

PELACANI, S.; LOMBARDI, L.; MAERKER, M. \& RODOLFI, G. Caratterizzazione dei processi geomorfici di versante nel bacino del torrente orme (Toscana Centrale) suIla base delle unita di risposta erosiva ERU. Genova: Ministero dell Università e Della Ricerca Progetti di Rilevante Interesse Nazionale, 2006b.

PERALTA, M. Estudio agrológico. Santiago: Comisión Nacional de Riego, 2004. Dis- 
ponible en Internet: http://www.chileriego.cl/ docs/015-06.doc

PIZARRO, R.; RAMÍREZ, C. y FLORES, J. Análisis comparativo de cinco métodos para la estimación de precipitaciones areales anuales en períodos extremos. Revista Bosque, 2003, No 24, p. 31-38.

RAPETTI, F.; SALVETTI, M. y SPAGNOLO, M. Carta geomorfológica del bacino del T. Roglio (Val d' Era - Toscana). 2002. En: RODOLFI, G.; DESSENA, M. y VACCA, S. II sistema idrografico FlumendosA-Mulargia: le acque, i suoli e i processi erosivi. Genova: Ediciones de la Università degli Studi di Firenze y Università degli Studi di Sassari, 2005.

RODOLFI, G. Erosione hídrica del suolo in ambiente mediterraneo: valutazione diretta e indirecta in aree Campione e Bacini idrografici. Genova: Ministero dell Università e Della Ricerca Progetti di Rilevante Interesse Nazionale, 2006.

SÁNCHEZ SAN ROMÁN, F. Precipitaciones. Salamanca: Departamento de Geología. Universidad de Salamanca, 2005.
SEGERSTROM, K. Geología de las hojas Copiapó y Ojos del Salado, Provincia de Atacama. Santiago: Instituto de Investigaciones Geológicas de Chile, boletín N²4, 1968.

SOTO, M.; CASTRO, C.; RODOLFI, G.; MARKER, M. y PADILLA, R. Procesos geodinámicos actuales en media y baja montaña, borde meridional de la cuenca del río Maipo, Región Metropolitana de Santiago. Revista de Geografía Norte Grande, 2006, Nº 35, p. 77-95.

SOTO, M.; CASTRO, C.; RODOLFI, G.; MARKER, M.; FERNÁNDEZ, R.; PADILLA, R. y RUGIERO, V. Carta geomorfológica de la sección central y occidental de la Región Metropolitana de Santiago. Informaciones Geográficas, 2007, №39, p. 91-104.

VILES, H. \& GOUDIE, A. Interannual, decadal and multidecadal scale climatic variability and geomorphology. Earth-Science Reviews, 2003, N61, p. 105-131.

WEISCHET, W. Zurgeomorphologie de Glatthang-Reliefs in der ariden subtropenzone des Kleines Nordens con Chile. Zeitschrift fur Geomorphologie, 1968, vol. 13, $N^{\circ} 1$, p. 1-21. 